\title{
Deactivation of Biacetyl Triplets by Cyanocobaltate(III) Complexes
}

\author{
By Mark Wrighton, Dale Bredesen, George S. Hammond, and Harry B. Gray* \\ (Arthur Amos Noyes Laboratory of Chemical Physics, California Institute of Technology, Pasadena, California 91109)
}

Summary The rate of electronic energy transfer from biacetyl triplets to $\mathrm{Co}(\mathrm{CN})_{5}(\mathrm{X})^{n-}\left(\mathrm{X}=\mathrm{CN}^{-}, \mathrm{MeCN}\right.$, pyridine, $\mathrm{N}_{3}^{-}, \mathrm{H}_{2} \mathrm{O}$, or $\mathrm{SCN}^{-}$) is strongly dependent on the energy of the first spin-allowed $d-d$ transition of $\mathrm{Co}(\mathrm{CN})_{5}(\mathrm{X})^{n-}$, and (for $\mathrm{X}=\mathrm{CN}^{-}, \mathrm{N}_{3}^{-}$, and $\mathrm{SCN}^{-}$) the direct and sensitized photosubstitution yields are the same, implying a common reactive state.

Electronically excited transition-metal complexes can play a key role in the quenching process of organic triplet excited states, as shown unequivocally by sensitizing the emission of some $\mathrm{Cr}^{\mathrm{III}}$ complexes using benzil ${ }^{1}$ and biacetyl. ${ }^{2}$ containing quenchers, and we show here that the rate of quenching of an organic triplet donor depends strongly on the energy of the lowest spin-allowed $d-d$ absorption band of the metal complex acceptor. Contrary to organic systems, the energy of the spin-forbidden emission for the metal complex may not always be a good indication of whether electronic energy transfer will occur at a diffusioncontrolled rate.

In the Table we summarize information obtained for interaction of some cyanocobaltate(III) complexes with biacetyl triplets in degassed aqueous solutions. $\dagger$ Direct photoaquation quantum yields for some of the complexes

TABLE. Interaction of cyanocobaltate(II) complexes with biacetyl triplets

$$
\text { Lowest spin-allowed }
$$

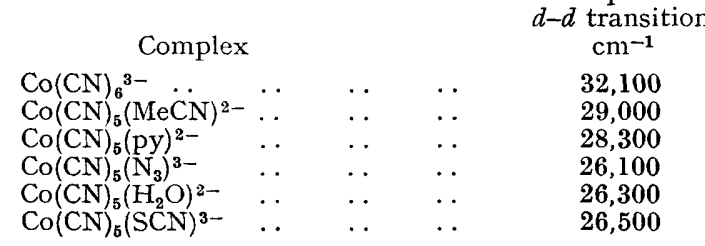

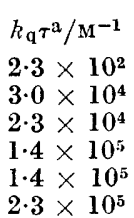

$\Phi_{\text {direet }}$
$0 \cdot 31^{b}$
$\quad \mathrm{c}$
$\mathrm{c}$
$0 \cdot 23^{\mathrm{d}}$
$2 \cdot 20^{\mathrm{d}}$

$\Phi_{\text {seusitized }}$
$0 \cdot 23^{\mathrm{b}}$
$\mathrm{c}$
$\mathrm{c}$
$0 \cdot 22^{\mathrm{d}}$
$0 \cdot 18^{\mathrm{d}}$

a Slope of plot of $I_{\mathrm{o}} / I$ [quencher]. b Aquation quantum yield from ref. 5 ; we find $\Phi_{\text {direct }}=0 \cdot 31$ at $313 \mathrm{~nm}, \Phi_{\text {sensitized }}=0 \cdot 23$. c Not determined. d Disappearance quantum yields, $436 \mathrm{~nm}$ irradiation.

Additional, though less direct, evidence of electronic energy transfer has been provided by several reports of sensitized reactions of metal complexes. ${ }^{3-6}$ Deactivation of organic triplet excited states by metal complexes without electronic excitation of the quencher is also important.1,2,7,8 We have investigated the efficiency of the electronic excitation mechanism of deactivation of organic triplets by metal- are included for comparison. Sensitization of $\mathrm{Co}(\mathrm{CN})_{5}\left(\mathrm{~N}_{3}\right)^{3-}$ and $\mathrm{Co}(\mathrm{CN})_{5}(\mathrm{SCN})^{3-}$ was not complicated by competing direct absorption of the $436 \mathrm{~nm}$ light. Both of these complexes exhibit ${ }^{12}$ intense charge-transfer bands in the u.v. enabling us to use very small amounts of the complex while still monitoring a significant change in absorbance since $\mathrm{Co}(\mathrm{CN})_{5}\left(\mathrm{H}_{2} \mathrm{O}\right)^{2-}$ absorbs relatively weakly. ${ }^{13}$ The amount

$†$ Quenching data were obtained by monitoring room-temperature phosphorescence intensity of the biacetyl as a function of quencher concentration. The fluorescence of biacetyl was unaffected. Emission measurements were made using an AmincoBowman spectrometer. Quantum yields for aquation were measured using a merry-go-round with appropriate filtering of a $450 \mathrm{~W}$ Hanovia lamp. Actinometry was either benzil-sensitized isomerization of stilbene (for $436 \mathrm{~nm}$ ) or direct trans $\rightarrow$ cis-stilbene isomerization (for $313 \mathrm{~nm}$ ). Quantum yield for the direct isomerization of trans-stilbene is $0.50^{9}$ and the benzil-sensitized trans $\rightarrow$ cis reaction quantum yield is $0.52 \mathbf{2 0}$ (corrected for inter-system crossing in benzil of $0 \cdot 87^{11}$ ). 
of quenching by $\mathrm{Co}(\mathrm{CN})_{5}\left(\mathrm{~N}_{3}\right)^{3-}$ and $\mathrm{Co}(\mathrm{CN})_{5}(\mathrm{SCN})^{3-}$ was virtually $100 \%$ at the concentrations employed $\left(\mathrm{ca} .10^{-4} \mathrm{M}\right)$. Quenching of the biacetyl phosphorescence by the metal complexes obeyed the Stern-Volmer relationship. No evidence for complex formation between biacetyl and $\mathrm{Co}(\mathrm{CN})_{5}(\mathrm{X})^{n-}$ was observed.

In agreement with Porter $^{3}$ we find that biacetyl sensitizes the photoaquation of $\mathrm{Co}(\mathrm{CN})_{5}(\mathrm{X})^{3-}$ complexes with efficiencies very similar to the direct irradiation yields. The rate of quenching is strongly dependent on the energy of the lowest observable $d-d$ absorption band of $\mathrm{Co}(\mathrm{CN})_{5}(\mathrm{X})^{3-}$ (Table), even though all the complexes should have lowerlying relaxed excited states than the biacetyl triplet. ${ }^{14}$ The key example here is $\mathrm{Co}(\mathrm{CN})_{6}{ }^{3-}$ which quenches slowly and yet exhibits spin-forbidden emission at an energy lower than biacetyl phosphorescence. Without thermal activation, the biacetyl triplet apparently does not have sufficient energy to facilitate a vertical $S \rightarrow T$ transition in $\mathrm{Co}(\mathrm{CN})_{8}{ }^{3-}$. Triplet acetone, however, which is at least $5000 \mathrm{~cm}^{-1}$ more energetic than triplet biacetyl, ${ }^{15}$ is quenched by $\mathrm{Co}(\mathrm{CN})_{6}{ }^{3-}$ at a diffusion-controlled rate and gives $\Phi_{\text {sens }}=0.23$ for aquation.

The $\mathrm{Co}(\mathrm{CN})_{5}(\mathrm{X})^{n-}$ complexes have spectroscopic states at lower energies than those for $\mathrm{Co}(\mathrm{CN})_{6}{ }^{3-}$ and quench biacetyl triplets at a correspondingly faster rate. The excited states produced in the direct irradiation undergo the same decay pathways as states produced by sensitization, which is consistent with the formation of spectroscopic triplet states by donors of triplet excitation.

This research was supported by the Directorate of Chemical Sciences, Air Force Office of Scientific Research, and the Army Research Office, Durham.

(Received, 12th June 1972; Com. 999.)

1 D. J. Binet, E. L. Goldberg, and L. S. Forster, J. Phys. Chem., 1968, 72, 3017.

2 V. Balzani, R. Ballardini, M. T. Gondolfi, and L. Moggi, J. Amer. Chem., 1971, 93, 339.

${ }^{3} \mathrm{G}$. B. Porter, $J$. Amer. Chem. Soc., 1969, 91, 3980.

${ }^{4}$ V. S. Sastri and C. H. Langford, J. Amer. Chem. Soc., 1969, 91, 7533.

5 A. Vogler and A. W. Adamson, J. Amer. Chem. Soc., 1968, 90, 5943.

${ }_{6}$ M. A. Scandola, F. Scandola, and V. Carassiti, Mol. Photochem., 1968, 1, 403.

? A. J. Fry, R. S. H. Liu, and G. S. Hammond, Mol. Photochem., 1966, 88, 4781.

8 V. Balzani and V. Carassiti, 'Photochemistry of Coordination Compounds,' Academic Press, London, 1970.

${ }^{9}$ S. Malkin and E. Fischer, J. Phys. Chem., 1964, 68, 1158.

10 H. A. Hammond, D. E. DeMeyer, and J. L. R. Williams, J. Amer. Chem. Soc., 1969, 91, 5180.

11 A. A. Lamola, Ph.D. Thesis, California Institute of Technology, Pasadena, 1965.

12 D. F. Gutterman and H. B. Gray, J. Amer. Chem. Soc., 1971, 93, 3364.

${ }^{13}$ L. Moggi, F. Bolletta, V. Balzani, and F. Scandola, J. Inorg. Nuclear Chem., 1966, 28, 2589.

14 The emission maximum for $\mathrm{Co}(\mathrm{CN})_{6}^{3-}$ is at $c a .14,400 \mathrm{~cm}^{-1}$ : M. Mingardi and G. B. Porter, J. Chem. Phys., 1966, 44, 4354; emission has not been observed for $\mathrm{Co}(\mathrm{CN})_{5}(\mathrm{X})^{n-}$ complexes, but these species should have lower lying excited states than $\mathrm{Co}(\mathrm{CN})_{6}{ }^{3-}$. We observe the biacetyl phosphorescence maximum at $c a .19,000 \mathrm{~cm}^{-1}$.

${ }_{15}$ N. J. Turro, 'Molecular Photochemistry,' Benjamin, New York, 1965, p. 179. 